VPMRT. Do đó một số tác giả chủ trương mổ mở trong VPMRT. Rách bao đựng RT cũng là một nguyên nhân gây nhiễm trùng vết mổ [1].

Như vậy nghiên cứu của chúng tôi cho thấy PTNS VPMRT tai các tỉnh miền núi phía Bắc khá an toàn với tỉ lệ biến chứng sớm là $1,7 \%$. Điều này cho thấy PTNS là một lựa chọn hợp lý trong điều trị VPMRT khi các PTV đã có kinh nghiệm và trang thiết bị đầy đủ tỉ lệ biến chứng rất thấp.

\section{KẾT LUÂ̂N}

Phẫu thuật nội soi viêm phúc mạc ruột thừa được ứng dụng tại các Bệnh viện đả khoa tỉnh miền núi phía Bắc cho thấy tính khả thi, hiệu quả, độ an toàn cao và tỉ lệ thành công lớn. Như vậy phẫu thuật nội soi trong điều trị viêm phúc mạc ruột thừa có thể được ứng dụng rộng rãi trong lâm sàng để giảm thiểu biến chứng và giúp bệnh nhân nhanh chóng bình phục.

\section{TÀI LIẸU THAM KHẢO}

1. Namir Katkhouda (2005), "Laparoscopic Versus Open Appendectomy A Prospective Randomized
Double-Blind Study", Annals of Surgery, pp. 135-145.

2. A. Yagmurlu (2006), "Laparoscopic appendectomy for perforated appendicitis: a comparison with open appendectomy", Surg Endosc., pp. 1051-1054.

3. F. Agresta (2004), "Direct trocar insertion vs veress needle in nonobese patients undergoing laparoscopic procedures: A randomized prospective single-center study", Surg Endosc., pp. 1778-1781.

4. Cueto J, D' Allemagne $B$, and Varquer - Frias JA, Et al (2006), "Morbidity of laparosopic surgery for complicated appendicitis: an inter national Study", Surg. Endosc. , pp. 717 - 720.

5. Yasuyuki Fukami (2007), "Value of Laparoscopic Appendectomy in Perforated Appendicitis", World J Surg., pp. 93-97.

6. CM Pring (2007), "Aortic injury using the Hasson trocar: a case report and review of the literature", Ann R Coll Surg Engl, pp. 89-91.

7. Kirsten Hall Long (2001), "A prospective randomized comparison of laparoscopic appendectomy with open appendectomy: Clinical and economic analyses", Surgery, pp. 390-400.

8. Goutaro Katsuno (2008), "Laparoscopic Appendectomy for Complicated Appendicitis: A Comparison with Open Appendectomy", World J Surg., pp. 208-214.

\title{
NGHIÊN CỨU ĐĂC ĐIỂM LÂM SÀNG VÀ KẾT QUẢ ĐIỀU TRI VẾT LOÉT CỦA LASER HE-NE TẠI BỆNH VIỆN DA LIỄU THÀNH PHỐ CẦN THO' NĂM 2020
}

\section{TÓM TẮT.}

Mục tiêu: Mô tả đặc điểm lâm sàng và đánh giá kết quả của laser He-Nie trong điều trị vết loét. Đối tượngvà phương pháp: Nghiên cứu mô tả có phân tích 30 bệnh nhân có vết loét điều trị bằng laser $\mathrm{He}$ Ne tai BV Da liê̂u TPCTnăm 2020. Kết quả: nhóm 4060 tuổi chiếm tỉ lệ cao nhất (56,7\%). 100\% bệnh nhân có đau nhứć, $46,7 \%$ sốt, $36,7 \%$ châm chích. Trước điều trị, điểm đau trung bình 3,2; kích thước trung bình 17,5mm; đô sâu trung bình $1 \mathrm{~mm}$; rì dich (93,3\%);mủ (10\%), viểm đỏ $(80 \%)$. Sau 72 giờ điều trị, điểm đau trung bình là 1,4; kích thước trung bình là 12,5mm; độ sâu trung bình là $0 \mathrm{~mm}$; rì dịch (30\%);mủ $(3,3 \%)$; viêm đỏ $(83,3 \%)$.Sau 72 giờ điêu trị, 56,7\% bệnh nhân giảm 25\% kích thước vết loét. Kết luâan: Sự giảm kích thước và độ sâu vết loét được ghi nhận từ 48 giờ sau điêu trị. Laser $\mathrm{He}-\mathrm{Ne}$ hằng ngày đển khi vết loét lành hoàn toàn hoặc tối thiểu 3 ngày được khuyến cáo điều trị.

*Trường Đại học Y Dước Cần Tho

Chịu trách nhiệm chính: Huỳnh Văn Bá

Email: bs.ba_fob@yahoo.com.vn

Ngày nhận bài: $13 / 6 / 2021$

Ngày phản biên khoa họ: 22/7/2021

Ngày duyệt băi: 25/8/2021

\author{
Dương Lê Hồng Thảo*, Trần Gia Hưng*, \\ Huỳnh Văn Bá*, Nguyễn Thị Thùy Trang* \\ Tư khóa: Laser He-Ne, vết loét, loét da mãn tính. \\ SUMMARY \\ DESCRIBE THE CLINICAL FEATURES AND \\ EVALUATE THE RESULTS OF HELIUM-NEON \\ LASER IN ULCER TREATMENT \\ Objective: Describe the clinical features and
} evaluate the results of Helium-Neon laser in ulcer treatment. Subjects and methods: Descriptive studies with analysis 30 patients were treated by Helium-Neon laser at Can Tho Hospital of DermatoVenereology in 2020. Results: $40-60$ years old people have the highest rate $(56,7 \%) .100 \%$ patients have experienced pain symptom; $46,7 \%$ fever. Before treatment, average VAS (Visual analog scales was 3,2; average size was $17,5 \mathrm{~mm}$; average depth was $1 \mathrm{~mm}$; ooze $(93,3 \%)$; pus $(10 \%)$, inflammation $(80 \%)$. After 72 hours of treatment, average VAS is 1.4; average size is $12,5 \mathrm{~mm}$; average depth is $0 \mathrm{~mm}$; ooze $(30 \%)$; pus $(3,3 \%)$, inflammation $(83,3 \%)$. After 72 hours of treatment, $56,7 \%$ of the patients have reduced $25 \%$ the size of the ulcers. Conclusion: A decrease in the size and depth of the ulcer was observed 48 hours after treatment. Helium-Neon laser daily until the lession is completely healed or for at least 3 days is recommended for treatment. 

ulcers.

Keywords: Ulcer, Helium-Neon laser, chronic skin

\section{I. ĐặT VẤN ĐỀ}

Loét da ảnh hưởng 0,6-3\% người trên 60 tuổi. Tỉ lệ này tăng dân theo tuổi, ở lứa tuổi 80 chiếm khoảng 5\%. Điêuu trị cổ điển đã mang lại kết quả nhất định nhưng thời gian kéo dài đặc biệt ở bệnh nhẩn đái tháo đường. Phối hợp điểu trị với laser Hé-Né cho thây kết quả đáng ghi nhận. Tại Bệnh viện Da liễu Thành phố Cần Thơ, laser He-Ne đã và đang được ứng dụng trong điêu trị các vết loét, tổn thương lâu lành. Trong quá trình điều trị, chúng tôi ghi nhận những kết quả điều trị thương tổn da, đặc biệt là vết loét khi phối hợp giữa phác đồ thuốc uống và Laser He-Ne cho kết quả nhanh chóng, sự cải thiện theo từng ngày là đáng ghi nhận.

Với sự quan sát lâm sàng như trên, chúng tôi thực hiện nghiên cứu "Nghiên cứu đặc điểm lâm sàng và kết quả điều trị vết loét của laser He-Ne tại Bệnh viện Da liễu Thành phố Cần Thơ năm 2020" với hai muc tiêu:

- Mô tả đặc điểm lâm sàng và các bệnh lý liên quan đến vết loét

- Đánh giá hiệu quả của Laser He-Ne trong điều trị vết loét

\section{II. ĐỐI TƯợNG VÀ PHƯƠNG PHÁP NGHIÊN CỨU}

1. Đối tượng nghiên cứu: Tất cả bệnh nhân có các thương tổn trợt loét trên 18 tuổi đến khám và điêuu trị tại Bệnh viện Da Liễu Cần Thơ.

Tiêu chuẩn chọn mẫu:

- Bệnh nhân bị các tổn thương trợt, loét đến khám và điều trị tại Bênh viên Da Liễu Cần Thơ.

- Được thăm khám, chẩn đoán và chỉ định điều trị với Laser He-Ne

- Bệnh nhân trên 18 tuổi

- Bệnh nhân đồng ý tham gia nghiên cứu

Tiêu chuẩn loại trừ: Bệnh nhân đã điều trị các thuốc đường toàn thân, có khả năng ức chế miễn dịch hay quá trình lành thương (corticoid, thuốc ức chế miên dịch, thuốc gây độc tế bào,...) trong vòng 72 giờ trước đó. Bệnh nhân có tình trạng suy giảm miễn dịch bẩm sinh và mắc phải. Bệnh nhân có tình trạng vết loét cân can thiệp ngoại khoa

Thời gian nghiên cứu: Từ tháng 05/2020 đến tháng 11/2020.

\section{Phương pháp nghiên cứu}

- Thiết kế nghiên cứu: Mô tả cắt ngang có phân tích.

- Phương pháp chọn mẫu: Chọn mẫu thuận tiện.

- Cõ mâu: Chọn tối thiểu 30 bệnh nhân.

- Công cụ nghiên cứu: Phiếu thu thập thông tin của bệnh nhân, phiếu đồng ý tham gia nghiên cứu, phiếu chỉ định điều trị Laser He-Ne, máy ảnh, thước.

Laser He-Ne được ứng dụng tại bệnh viện là máy Laser TeraMed và Nacenlas. Hệ thống Laser He-Ne năng lượng thấp có khả năng tạo ra bước sóng $650 \mathrm{~nm}$, với công suất từ $10 \mathrm{~mW}$. Thời gian chiếu: 15 phút. Khoảng cách từ đâuu chiếu đến vết thương khoảng $30 \mathrm{~cm}$.

- Phương pháp xử lý và phân tích số liệu:

- Số liệu được nhập, mã hóa và xử lý bằng phân mềm R Thống kê mô tả:

- Các biến số định tính được trình bày dưới dạng tân số và tỉ lệ phân trăm.

- Các biến số định lượng được trình bày dưới dạng giá trị trung bình và độ lệch chuẩn nếu là phân phối chuẩn và dạng trung vị, giá trị nhỏ nhất, giá trị lớn nhất nếu không phải phân phối chuẩn.

\section{Thống kê phân tích:}

- Dùng phép kiểm Chi bình phương (X2) hoăc phép kiểm định Fisher's (vọng trị nhỏ) để kiểm định mối liên quan giữa 2 hay nhiêu biến định tính.

- Dùng phép kiểm Chi bình phương $(x 2)$ để kiểm định mối liên quan giữa 2 hay nhiều biến định tính.

- Dùng phép kiểm Student (nếu là phân phối chuẩn) và phép kiểm Mann-Whitney U (nếu không là phân phối chuẩn) để so sánh 2 số trung bình. Phép kiểm ANNOVA để so sánh từ 3 số trung bình trở lên.

- Phép kiểm tương quan Spearman (Spearman rank correlation test) để tìm mối tương quan.

- Sự khác biệt được xem có ý nghĩa thống kê khi $\mathrm{p}<0,05$ với độ tin cậy 95\%.

\section{KẾT QUẢ NGHIÊN CỨU}

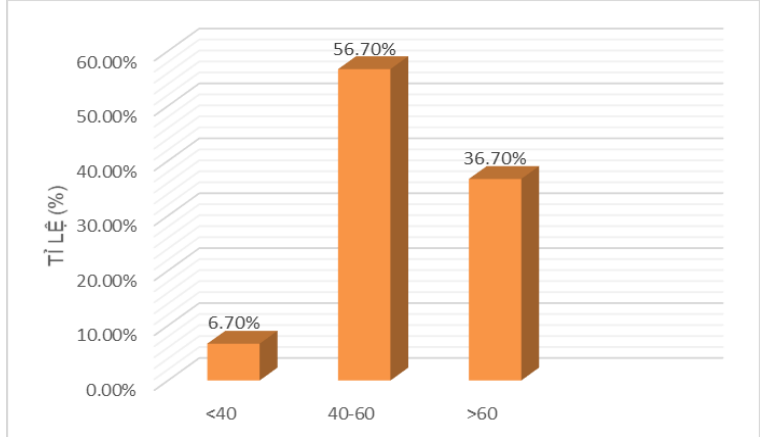

Biểu đồ 1. Phân bố bệnh nhân theo tỉ lệ từng nhóm tuôi $(n=30)$

Nhân xét: nhóm tuổi 40-60 tuổi chiếm tỉ lệ cao nhất $(56,7 \%)$, kế đến là nhóm $>60$ tuổi $(36,7 \%)$ và chiếm tỉ lệ thấp nhất là nhóm <40 tuổi $(6,7 \%)$. 


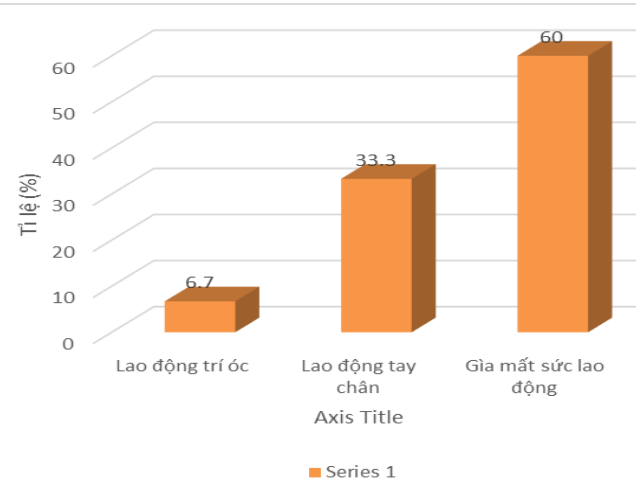

Biểu đồ 2. Phân bố bệnh nhân theo nghề nghiệp $(n=30)$

Nhận xét: Nhóm già mất sức lao động chiếm tỉ lệ cao nhất $(60 \%)$, kế đến là nhóm lao động tay chân $(33,3 \%)$. Nhóm lao động trí óc chiếm tỉ lệ thấp nhất $(6,7 \%)$.

Bảng 1. Thời gian mắc bệnh

\begin{tabular}{|c|c|c|c|c|}
\hline $\begin{array}{c}\text { Thừi gian } \\
\text { mắc bệnh }\end{array}$ & $\mathbf{n}$ & $\begin{array}{c}\text { Trung } \\
\text { vị }\end{array}$ & $\begin{array}{c}\text { Nhỏ } \\
\text { nhất }\end{array}$ & $\begin{array}{c}\text { Lớn } \\
\text { nhất }\end{array}$ \\
\hline Ngày & 30 & 14 & 3 & 180 \\
\hline
\end{tabular}

Nhận xét: Trong mẫu nghiên cứu này, thời gian mắc bệnh của bệnh nhân trung bình là 14 ngày (nhỏ nhất 3 ngày, lớn nhất 180 ngày).

Bảng 2. Điêm đau theo thang đo VAS

\begin{tabular}{|c|c|c|}
\hline Thang VAS & Tân số (n) & Tỷ lệ (\%) \\
\hline $\mathrm{TB} \pm \mathrm{SD}$ & \multicolumn{2}{|c|}{$3,2 \pm 1,7$} \\
\hline 1 & 3 & 10 \\
\hline 2 & 5 & 16,7 \\
\hline 3 & 17 & 56,7 \\
\hline 5 & 3 & 10 \\
\hline 8 & 1 & 3,3 \\
\hline 9 & 1 & 3,3 \\
\hline Tống & 30 & 100 \\
\hline
\end{tabular}

Nhận xét: Trong mẫu nghiên cứu này, điểm đau của bệnh nhân trung bình là $3,2(1,5-4,9)$.

Bảng 3. Kích thước và độ sâu vết loét

\begin{tabular}{|c|c|c|c|c|}
\hline Đặc điểm & $\mathbf{n}$ & $\begin{array}{c}\text { Trung } \\
\text { vị }\end{array}$ & $\begin{array}{c}\text { Nhỏ } \\
\text { nhất }\end{array}$ & $\begin{array}{c}\text { Lớn } \\
\text { nhất }\end{array}$ \\
\hline
\end{tabular}

\begin{tabular}{|c|c|c|c|c|}
\hline $\begin{array}{c}\text { Kích thước } \\
(\mathrm{mm})\end{array}$ & 30 & 17,5 & 10 & 100 \\
\hline $\begin{array}{c}\text { Độ sâu } \\
(\mathrm{mm})\end{array}$ & 30 & 1 & 1 & 3 \\
\hline
\end{tabular}

Nhân xét: Trong mẫu nghiên cứu này, kích thước vết loét trung bình là $17,5 \mathrm{~mm}$ (nhỏ nhất $10 \mathrm{~mm}$, lớn nhất $100 \mathrm{~mm}$ ). Độ sâu vết loét trung bình là $1 \mathrm{~mm}$ (nhỏ nhất 1mm, lớn nhất 3mm).

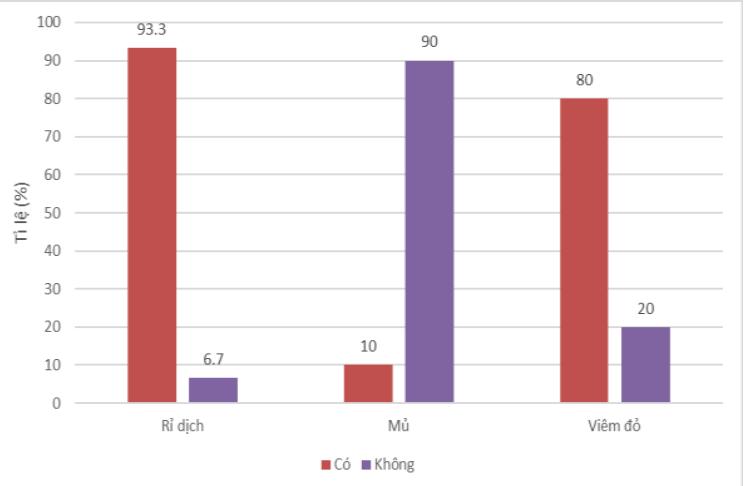

Biểu đồ 3. Đăc điểm vêt loét

Nhân xét: Vết loét rỉ dịch chiếm $93,3 \%$, có mủ chiếm $10 \%$, viêm đỏ chiếm $80 \%$.

Bảng 4. Mức độ cái thiện điểm đau sau 24, 48, 72 giờ điều trí

\begin{tabular}{|c|c|c|c|}
\hline $\begin{array}{c}\text { Thang } \\
\text { VAS }\end{array}$ & $\begin{array}{c}\text { Sau 24 } \\
\text { giờ }\end{array}$ & $\begin{array}{c}\text { Sau 48 } \\
\text { giờ }\end{array}$ & $\begin{array}{c}\text { Sau 72 } \\
\text { giờ }\end{array}$ \\
\hline $\mathrm{TB} \pm S D$ & $2,7 \pm 1,5$ & $1,9 \pm 1,3$ & $1,4 \pm 1,2$ \\
\hline 0 & 0 & $3(10)$ & $7(23,3)$ \\
\hline 1 & $7(23,3)$ & $9(30)$ & $11(36,7)$ \\
\hline 2 & $7(23,3)$ & $13(43,3)$ & $8(26,7)$ \\
\hline 3 & $11(36,7)$ & $2(6,7)$ & $2(6,7)$ \\
\hline 4 & $3(10)$ & $1(3,3)$ & $1(3,3)$ \\
\hline 5 & 0 & $1(3,3)$ & $1(3,3)$ \\
\hline 6 & 0 & $1(3,3)$ & 0 \\
\hline 7 & $2(6,7)$ & 0 & 0 \\
\hline Tống & $\mathbf{3 0}(\mathbf{1 0 0})$ & $\mathbf{3 0}(\mathbf{1 0 0})$ & $\mathbf{3 0 ( 1 0 0 )}$ \\
\hline
\end{tabular}

Nhận xét: Trong mầu nghiên cứu này, điểm đau trung bình của bệnh nhân sau 24 giờ điều trị là $2,7(1,2-4,2)$, sau 48 giờ điêu trị là $1,9(0,6-$ $3,2)$, sau 72 giờ điêu trị là $1,4(0,2-2,6)$.

Bảng 5. Mức độ cải thiện kích thước và độ sâu vết loét

\begin{tabular}{|c|c|c|c|c|c|c|}
\hline \multirow{2}{*}{ Đặc điểm } & \multicolumn{2}{|c|}{ Sau 24 giờ } & \multicolumn{2}{c|}{ Sau 48 giờ } & \multicolumn{2}{c|}{ Sau 72 giờ } \\
\cline { 2 - 7 } & $\begin{array}{c}\text { Trung } \\
\text { vị }\end{array}$ & $\begin{array}{c}\text { Nhỏ nhất- } \\
\text { lớn nhất }\end{array}$ & $\begin{array}{c}\text { Trung } \\
\text { vị }\end{array}$ & $\begin{array}{c}\text { Nhỏ nhất- } \\
\text { lớn nhất }\end{array}$ & $\begin{array}{c}\text { Trung } \\
\text { vị }\end{array}$ & $\begin{array}{c}\text { Nhó nhất-Iớn } \\
\text { nhất }\end{array}$ \\
\hline Kích thước $(\mathrm{mm})$ & 16 & $8-95$ & 13,5 & $7-80$ & 12,5 & $5-65$ \\
\hline Độ sâu $(\mathrm{mm})$ & 1 & $1-2$ & 1 & $1-2$ & 0 & $0-1$ \\
\hline
\end{tabular}

\section{BÀN LUÂ̂N}

Chúng tôi thực hiện nghiên cứu trên 30 bệnh nhân đến khám và điều trị vết loét tại Bệnh viện Da liễu Cần Thơ từ tháng 05/2020 đến 11/2020, sau 3 ngày theo dõi điều trị.Trong nghiên cứu của chúng tôi nhận thấy nhóm tuổi 40-60 tuổi chiếm tỉ lệ cao nhất $(56,7 \%)$, kễ đến là nhóm $>60$ tuổi $(36,7 \%)$ và chiếm tỉ lệ thấp nhất là nhóm $<40$ tuổi $(6,7 \%)$. Theo một số tài liệu, giới tính không ảnh hưởng đến việc phát triển vết loét, tức là tỉ lệ nam và nữ bị bệnh không có nhiều khác biệt. Nghiên cứu của chúng tôi ghi 
nhận tỉ lệ nam: nữ là 1:1.

Trình độ học vấn là yếu tố quan trọng ảnh hưởng đến sự hiểu biết về bệnh tật cũ̃ng như tuân thủ điều trị của bệnh nhân. Người bệnh cần biết về bệnh của mình cũng như các yếu tố nguy cớ, tiền sử cá nhân, các yếu tố làm bệnh nặng hơn cũng như cách phát hiện sớm biến chứng. Nghiên cứu của chúng tôi cho thấy bệnh nhân có trình độ học vấn cấp 2 chiếm tỉ lệ cao nhất $(36,7 \%)$, thấp nhất là mù chữ $(3,3 \%)$.

Trong nghiên cứu của chúng tôi, nhóm già mất sức lao động chiếm tỉ lệ cao nhất (60\%). Bên cạnh đó, nhóm lao động tay chân chiếm tỉ lệ cao $(33,3 \%)$. Chúng tôi cho rằng nhóm lao động tay chân tiếp xúc nhiều với dụng cụ làm vườn, cây cối,... là một yếu tố nguy cơ gây ra vết loét. Nhóm lao động tay chân có vết loét chiếm tỉ lệ cao hơn nhóm lao động trí óc.

100\% bênh nhân có đau nhức, 46,7\% bênh nhân có sốt, 36,7\% bệnh nhân có châm chích, 13,3\% bệnh nhân có cảm giác bỏng rát tại chỗ.

Trong mẫu nghiên cứu này, điểm đau của bệnh nhân trung bình là 3,2 (1,5 - 4,9). Nghiên cứu của chúng tôi ghi nhận bệnh nhân có điểm đau 8, 9 theo thang đo VAS, ghi nhận tình trạng bệnh ảnh hưởng nghiêm trọng đến chất lượng cuộc sống của bệnh nhân.

Nghiên cứu của chúng tôi ghi nhận kích thước vết loét trung bình là $17,5 \mathrm{~mm}$ (nhỏ nhất $10 \mathrm{~mm}$, lớn nhất $100 \mathrm{~mm}$ ). Độ sâu vết loét trung bình là $1 \mathrm{~mm}$ (nhỏ nhất 1mm, lớn nhất $3 \mathrm{~mm}$ ).

Nghiên cứu của Nguyễn Khang Sơn (2012) khoan nông giác mạc thỏ tạo vết loét đường kính $4 \mathrm{~mm}$, độ sâu $3 \mathrm{~mm}$. Khi rút kim, chỉ giác mạc là phương tiện đưa vi khuẩn vào vết loét.

Vết loét rỉ dịch chiếm $93,3 \%$, có mủ chiếm $10 \%$, viêm đỏ chiếm $80 \%$.

Nghiên cứu của chúng tôi ghi nhận triệu chứng đau nhức bắt đầu giảm từ $24 \mathrm{~h}$ đầu tiền sau điều trị $(90 \%)$, sau 48 h điều trị $(87,7 \%)$, sau $72 \mathrm{~h}(76,7 \%)$. Triệu chứng đau nhức giảm nhiều nhất từ sau $72 \mathrm{~h}$ điều trị.Triệu chứng sốt bắt đâu giảm từ $24 \mathrm{~h}$ đầu tiên sau điều trị $(46,7 \%)$, mức độ giảm sốt tương ứng với thời gian điêu trị. Triệu chứng châm chích có giảm từ ngày đầu tiên điều trị nhưng giảm chậm từ $36,7 \%$ còn 23,3\% sau 72 giờ điều trị. Triệu chứng ớn lạnh không giảm vào ngày đầu tiên điều trị, bắt đầu đáp ứng với điều trị từ sau 48 giờ. Triệu chứng bỏng rát không giảm sau 24 giờ điều trị, bắt đầu đáp ứng với điều trị từ sau 48 giờ. Tî lệ giảm triệu chứng ớn lạnh và bỏng rát giảm chậm. Trong mẫu nghiên cứu này, điểm đau trung bình của bệnh nhân sau 24 giờ điều trị là 2,7 (1,2-
$4,2)$, sau 48 giờ điều trị là $1,9(0,6-3,2)$, sau 72 giờ điêu trị là 1,4 (0,2-2,6).

\section{KẾT LUÂN}

Đặc điểm lâm sàng của thương tổn vết loét phong phú. Thương tổn thường gặp ở bệnh nhân > 40 tuổi $(93,4 \%)$.

Thời gian bệnh nhân từ lúc khởi phát triệu chứng đến khi đến bệnh viện điều trị trung bình là 14 ngày.

Đa số bệnh nhân ghi nhận tiền sử bệnh lí $(50 \%)$, trong đó tiền sử bệnh đái tháo đường chiếm tỉ lệ cao nhất (26,7\%).

Triệu chứng đau nhức chiếm tỉ lệ cao nhất (100\%). 63,3\% bệnh nhân có triệu chứng châm chích. $46,7 \%$ bệnh nhân có sốt.

Nhóm lao động tay chân, người già mất sức lao động chiếm tỉ lệ cao nhất.

Các yếu tố làm vết loét nặng hơn: tuổi càng cao, tiền sử (đái tháo đường, tăng huyết áp, bệnh zona, bệnh phong). Thời gian mắc bệnh càng lâu thì kích thước vết loét càng lớn.

Kết quả điều trị vết loét bằng laser $\mathrm{He}-\mathrm{Ne}$ : Sau 24 giờ điều trị bằng laser $\mathrm{He}-\mathrm{Ne}, 100 \%$ bệnh nhân giảm triệu chứng đau nhức, sốt, chưa ghi nhận giảm > 25\% kích thước vết loét.Sau 48 giờ điều trị, $30 \%$ bệnh nhân giảm $25 \%$ kích thước vết loét. Sau 72 giờ điều trị bằng laser $\mathrm{He}-\mathrm{Ne}, 56,7 \%$ bệnh nhân giảm $25 \%$ kích thước vết loét, 16,7\% bệnh nhân giảm $50 \%$ kích thước vết loét. $26,7 \%$ bệnh nhân giảm <25\% kích thước vết loét.

\section{KIẾN NGH!}

1. Sau 72 giờ điêu trị, có $73,3 \%$ bệnh nhân có đáp ứng với điều trị. Vì vậy, laser Hé-Né hằng ngày đến khi vết loét lành hoàn toàn nên được khuyến cáo điều trị, đặc biệt đối với bệnh nhẩn lớn tuổi, có tiền sử bệnh lí (đái tháo đường, tăng huyết áp, bệnh zona).

2. Việc chậm trễ điều trị cho thấy đáp ứng kém hơn nhóm đến sớm trước 14 ngày. Vì vậy cần tổ chức các buổi sinh hoạt chuyên đề để cung cấp thêm kiến thức cho bệnh nhân phát hiện sớm triệu chứng vết loét cũng như giáo dục bệnh nhân tuân thủ điều trị theo hướng dẫn của bác sĩ.

\section{TÀI LIỆU THAM KHẢO}

1. Bộ môn Da Liễu Đại học Y Hà Nội (2017), "Ứng dụng lašer trong chuyên ngành da liểu", Bệnh học da liễu tập 3 (Sách đào tạo sau đại học), Hà Nội, tr. 411-429.

2. Bộ mốn Da Liễu Trường Đại học $Y$ Dược Cân Thरo (2019), "Thương tổn căn bản", Giáo trình Da Liễu, Hà Nội tr. 1-7.

3. Nguyễn Quang Sơn (2012), "So sánh sự hồi phục cấu trúc giác mạc thỏ bị viêm loét do tụ cầu 
được điều trị dài ngày bằng laser Helium-Neon đơn thuần và laser phối hợp với kháng sinh", Y học thực hành (802), tr. 8-10.

4. Allameh $\mathbf{M}$ et al (2018), "Comparative evaluation of the efficacy of laser therapy and fibroblastic growth factor injection on mucosal wound healing in rat experimental model", Journal of Lasers in Medical Sciences, 9 (3), pp. 194-199.

5. Elisa M, Salih WHM (2017), "The influence of low-intensity He-Ne laser on the wound healing in diabetic rats", Lasers Med Sci, 32 (6), pp. 1261-
1267.

6. Gonzalez AC, Costa TF, Andrade ZA et al. (2016), "Wound healing - A literature review", An Bras Dermatol, 91 (5), pp. 614-620.

7. Lopez A, Brundage C (2019), "Wound photobiomodulation treatment: Outcomes in animal models", Journal of Veterinary Medicine.

8. Sardari F, Ahrari F (2016), "The effect of lowlevel helium-neon laser on oral wound healing", Dent Res J (Isfahan), 13 (1), pp. 24-29.

\section{ĐÁNH GIÁ KẾT QUẢ CHỤP TUỶ GIÁN TIẾP RĂNG HÀM SỮA THỨ HAI CÓ SỬ DƯNG MINERAL TRIOXIDE AGGREGATE TAI BÊ̂NH VIÊ̂N RĂNG HÀM MẶT TRUNG ƯO'NG HÀ NộI NĂM 2020-2021}

\section{TÓM TẮT}

Mục tiêu: Đánh giá kết quả chụp tủy gián tiếp răng hàm sữa thứ hai sâu ngà có sử dung Mineral Trioxide Aggregate (MTA) ở nhóm bệnh nhân trẻ em đến khám tai bênh viện Răng Hàm măt TW Hà Nội. Đối tượngvà phương pháp: 45 bệnh nhân 5 -9 tuổi với 56 răng hàm sữa thứ hai sâu ngà mà không có dấu hiệu hay triệu chứng của bệnh lý tủy.Sau khi thăm khám lâm sàng và Xquang, các răng này được tiến hành chụp tủy gián tiếp sử dụng MTA làm vật liệu chup tủy. Đánh giá kết quả trên lâm sàng và cận lậm sàng sau 3 tháng. Kết quả: Sau 3 tháng, trong tổng số 56 răng can thiệp tỷ lệ răng có triệu chứng đau khi gõ, lợi nề đỏ, lung lay bệnh lý,bong/ vỡ mối hàn lần lượt là $1,8 \%$. Đánh giá trên Xquang, các triệu chứng lố sâu lan rộng đến tủy, thấu quang vùng chẽ, dãn rộng dây chằng quanh răng lấn lượt chiếm tỷ lệ 1,8\%.Tỷ lệ thành công sau 3 tháng chụp tủy gián tiếp sử dụng MTA là 96,4\%. Kết luận: Phương pháp chụp tủy gián tiếp có hiệu quả trong bảo tồn tính sống của tủy răng sữa. MTÁ là vật liệu nên được sử dụng để chụp tủy gián tiếp cho răng sữa.

Tư khóa: Chụp tủy gián tiếp, Mineral Trioxide Aggregate, răng hàm sữa.

\section{SUMMARY}

CLINICAL AND RADIOGRAPHIC

EVALUATION OF INDIRECT PULP

TREATMENT WITH MTA IN PRIMARY SECOND MOLARS

Objectives: To evaluate clinical and radiographic outcomes of indirect pulp capping in primary second molars over a period of 3 months. Subjects and

*Bệnh viện Răng Hàm Mặt TW Hà Nội

Chiu trách nhiệm chính: Pham Doãn Thùy Trâm

Email: thuytram_174@yahoo.com

Ngày nhận bài: 10/7/2021

Ngày phản biện khoa học: 8/8/2021

Ngày duyệt bài: 26/8/2021

\section{Phạm Doãn Thùy Trâm*, Phạm Thanh Hà*}

methods: A clinical trial with sample size of 45 patients between the age group of 5-9 years old, with 56 primary second molars with deep carious lesions without signs and symptoms of irreversible pulpitis. Indirect pulp capping was applied using MTA. Clinical and radiographic findings were evaluated after 3 months. Result: After 3 months follow up, the rate of teeth with pain upon percussion, gum swelling/abscess, pathologic mobility,loss/ broken of restoration was $1,8 \%$, respectively. On radiographic evaluation, the radiological pathologycan be observed at the respective rate of $1,8 \%$. The success rate of indirect pulp cappingusing MTA was $96,4 \%$. Conclusions: The result support the idea that the success of Indirect Pulp capping (IPC) for primary teeth with deep caries. MTA is a good IPC medicament in primary teeth.

Keywords: Indirect pulp treatment, mineral trioxide aggregate, primary teeth.

\section{I. ĐĂT VẤN ĐỀ}

Bệnh sâu răng vẫn luôn là bệnh lý chiếm tỷ lệ cao trong các bệnh lý về răng miệng ở trẻ em [1]. Sâu răng sữa thường tiến triển nhanh, nêú không được điều trị sẽ dẫn tới các bênh lý tuỷ răng và các biến chứng khác gây sưng đau ảnh hưởng đến ăn nhai, không ngủ được từ đó ảnh hưởng đênn sức khoẻ toàn thân của trẻ [2]. Với những răng có lỗ sâu sát tủy nếu được điều trị đúng cách sẽ đơn giản, nhẹ nhàng và tránh sang chấn tâm lý cho trẻ em.

Phương pháp chup tuỷ gián tiếp trong điều trị bảo tồn tính sống của tủyrăng đã phát triển trên thế giới trong nhiều năm gần đây cho thấy chi phí điều trị thấp hơn, đạt tỉ lệ thành công cao tránh được biến chứng viêm tuỷ trở lai hơn so với phương pháp điêu trị tuỷ buồng [3]. Sự ra đời của các vật liệu mới như MTA đã làm thay đổi quan điểm điểu trị. MTA là một vật liệu lý 